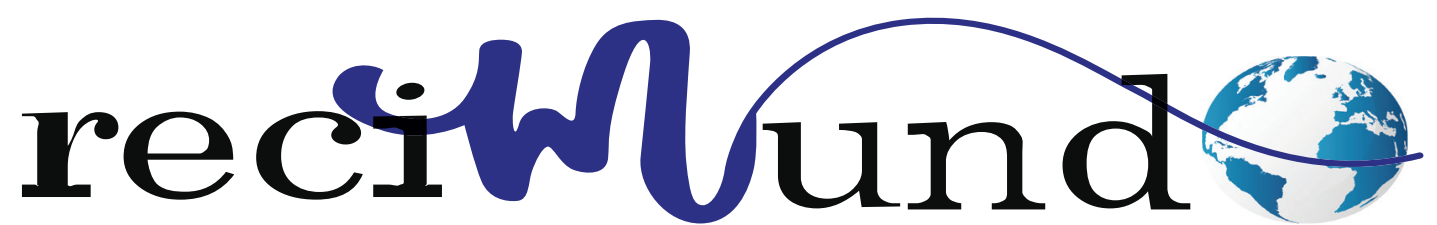

Revista Científica Mundo de la Investigación y el Conocimiento

DOI: 10.26820/recimundo/4.(1).esp.marzo.2020.24-45

URL: http://recimundo.com/index.php/es/article/view/775

EDITORIAL: Saberes del Conocimiento

REVISTA: RECIMUNDO

ISSN: 2588-073X

TIPO DE INVESTIGACIÓN: Artículo de Revisión

CÓdigo UNESCO: 3201 Ciencias Clínicas

PAGINAS: 24-45

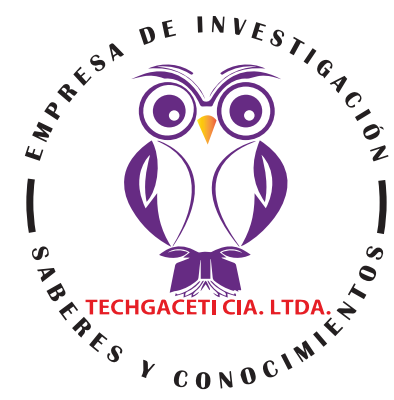

\title{
Desnutrición infantil kwashiorkor
}

\section{Child malnutrition kwashiorkor}

\section{Desnutrição infantil kwashiorkor}

Andrea Enriqueta Naranjo Castillo1; Virginia Anabell Alcivar Cruz²; Thaylandia Stefanie Rodriguez Villamar;

Freddy Alberto Betancourt Bohórquez ${ }^{4}$

\section{RECIBIDO: 20/11/2019 ACEPTADO: 29/01/2020 PUBLICADO: 05/03/2020}

1. Diploma Superior en Atención Primaria en Salud; Médico; Investigadora Independiente; Guayaquil, Ecuador; anaranjoc84@hotmail.com; iD https://orcid.org/0000-0001-9762-2778

2. Médico; Investigadora Independiente; Guayaquil, Ecuador; anabellalcivar21@hotmail.es; (D) https://orcid. org/0000-0002-4446-0004

3. Médico; Investigadora Independiente; Guayaquil, Ecuador; drathaylandia@hotmail.com; (iD https://orcid.org/0000-0001-7937-909X

4. Médico; Investigador Independiente; Guayaquil, Ecuador; fsoruf@gmail.com; iD https://orcid.org/0000-00016327-6440

CORRESPONDENCIA

Andrea Enriqueta Naranjo Castillo

anaranjoc84@hotmail.com

Guayaquil, Ecuador 


\section{RESUMEN}

El cuerpo humano desarrolla diversas actividades que involucran grandes fuerzas, desarrollos físicos y habilidades psicológicas que requieren de grandes cantidades de energía. Esta energía proviene de una alimentación balanceada y correcta en la etapa infantil. En esta etapa, los órganos del cuerpo humano se desarrollan por lo que la ingesta de alimentos debe ser la correcta. Un desequilibrio en esta relación puede ocasionar a futuro la aparición de enfermedades que pueden disminuir la calidad de vida. Al no producirse el equilibrio en la alimentación entonces lo que se afronta es un grave problema de desnutrición infantil. Esto hace que exista una falta de nutrientes específicos en el organismo como,por ejemplo, una insuficiencia de proteico en esta etapa de desarrollo. Esto último da origen al kwashiorkor. Por lo cual, esta investigación tiene como objetivo general analizar la influencia de la desnutrición infantil kwashiorkor. La metodología empleada se basó en investigación de carácter documental y bibliográfica. Los resultados se basaron en la importancia de la desnutrición infantil, la influencia de la proteína en la niñez y las características del kwashiorkor. Como conclusión, se obtuvo que la falta de proteínas en la niñez puede producir una falta de desarrollo cognitivo y físico a lo largo del tiempo, por lo que se debe realizar un diagnóstico por medio de una exploración física al niño, midiendo talla y peso para relacionarlo con la edad y el sexo, aunado a un interrogatorio a la madre sobre la dieta alimentaria, así como también el tratamiento basado en un protocolo otorgado por la OMS, basado en la severidad del diagnóstico y trata principalmente en la atención de la hipoglucemia, deshidratación, electrolitos, alimentación prudente, crecimiento y apoyo emocional.

Palabras clave: Alimentación, Proteínas, Desnutrición Infantil, Kwashiorkor.

\section{ABSTRACT}

The human body develops various activities that involve large forces, physical developments and psychological skills that require large amounts of energy. This energy comes from a balanced and correct diet in the infant stage. At this stage, the organs of the human body develop so that food intake must be correct. An imbalance in this relationship may lead to the onset of diseases that may decrease the quality of life. When there is no equilibrium in food then what is faced is a serious problem of child malnutrition. This causes a lack of specific nutrients in the body such as, for example, a lack of protein at this stage of development. The latter gives rise to kwashiorkor. Therefore, this research has as a general objective to analyze the influence of child malnutrition kwashiorkor. The methodology used was based on documentary and bibliographic research. The results were based on the importance of childhood malnutrition, the influence of protein in childhood and the characteristics of kwashiorkor. In conclusion, it was obtained that the lack of proteins in childhood can produce a lack of cognitive and physical development over time, so a diagnosis must be made through a physical examination of the child, measuring height and weight to relate it to age and sex, together with an interrogation of the mother about the food diet, as well as the treatment based on a protocol granted by the WHO, based on the severity of the diagnosis and mainly deals with the care of hypoglycemia, dehydration, electrolytes, prudent food, growth and emotional support.

Keywords: Food, Proteins, Child Malnutrition, Kwashiorkor.

\section{RESUMO}

O corpo humano desenvolve várias atividades que envolvem grandes forças, desenvolvimentos físicos e habilidades psicológicas que requerem grandes quantidades de energia. Essa energia provém de uma dieta equilibrada e correta no estágio infantil. Nesta fase, os órgãos do corpo humano se desenvolvem para que a ingestão de alimentos seja correta. Um desequilíbrio nessa relação pode levar ao aparecimento de doenças que podem diminuir a qualidade de vida. Quando não há equilíbrio nos alimentos, o que é enfrentado é um sério problema de desnutrição infantil. Isso causa falta de nutrientes específicos no corpo, como, por exemplo, falta de proteínas nesta fase do desenvolvimento. Este último dá origem ao kwashiorkor. Portanto, esta pesquisa tem como objetivo geral analisar a influência da desnutrição infantil kwashiorkor. A metodologia utilizada foi baseada em pesquisa documental e bibliográfica. Os resultados foram baseados na importância da desnutrição infantil, na influência das proteínas na infância e nas características do kwashiorkor. Concluindo, foi obtido que a falta de proteínas na infância pode produzir falta de desenvolvimento cognitivo e físico ao longo do tempo; portanto, um diagnóstico deve ser feito através de um exame físico da criança, medindo altura e peso para relacioná-la com idade e sexo. , juntamente com um interrogatório da mãe sobre a dieta alimentar, bem como o tratamento com base em protocolo concedido pela OMS, com base na gravidade do diagnóstico e lida principalmente com os cuidados de hipoglicemia, desidratação, eletrólitos, alimentos prudentes, crescimento e apoio emocional.

Palavras-chave: Alimentos, proteínas, desnutrição infantil, Kwashiorkor. 


\section{Introducción}

El cuerpo humano desarrolla diversas actividades que involucran grandes fuerzas, desarrollos motores y habilidades psicológicas que requieren de grandes cantidades de energía. Esta energía es adquirida, en gran parte, por los alimentos que ingiere el individuo, haciendo que deba existir un equilibrio entre la calidad y cantidad con los gastos energéticos realizados por la persona.

Además, los alimentos son parte fundamental del desarrollo humano y su calidad y composición se han coinvertido en parte fundamental en la dieta de los seres humanos. Desde el punto de vista social se han convertido en la base fundamental de la sociabilidad, característica importante en el desarrollo humano. La alimentación es una consecuencia de nuestra adaptación al entorno,por lo que, el comer de una manera es la consecuencia del reflejo del orden social predominante dentro de una sociedad determinada(Hernandes \& Armaiz, 2007).

Es decir que, dependiendo del entorno, la calidad de los alimentos que se digieren depende del entorno y a su vez de la actividad socioeconómica que tenga el grupo social. Esto puede producir una variabilidad en la calidad de los alimentos. Si la ingesta de alimentos no es controlada o no es balanceada se manifiesta un desequilibrio en el organismo, por lo que se pueden convertir en agentes catalizadores de múltiples enfermedades.

Entonces, es necesario poder comprender la finalidad del alimento y, más, el alimento balanceado que ayuda a mantener la estabilidad del cuerpo humano. El alimento es cualquier sustancia ingerida por el organismo que tiene como finalidad el mantenimiento de las funciones vitales o generar en él una satisfacción sin alterar su normal funcionamiento del organismo(Cide@d, 2020). Ahora, el alimento balanceado es una alimentación que proporciona una cantidady variedad de alimentos suficiente para cubrir las necesidades de energía yde nutrientes de una persona(FAO, Nutrientes en los alimentos, 2020).

Así mismo, la alimentación debe ser balanceada y correcta debido a la importancia que tiene para diversas funciones del organismo. La alimentación correcta es la base de una buena salud junto con el consumo de agua potable y la práctica de actividad física, ya que es la mejor manera de prevenir y controlar el sobrepeso, obesidad y otras enfermedades(IMSS, 2020). En la Figura 1, se puede observar el plato del bien comer donde se refleja los alimentos necesarios para una alimentación correcta.

Existen también, una serie de alimentos que cumplen con funciones específicas para ayudar al equilibrio en los diversos sistemas del cuerpo humano. Estos son los alimentos funcionales. Cualquier alimento en forma natural o procesada, que además de sus componentes nutritivos contiene componentes adicionales que favorecen a la salud, la capacidad física y el estado mental de una persona(Alvídrez-Morales, González-Martínez, \& Jiménez-Salas,, 2002).

Una de las etapas cruciales para el desarrollo del individuo es una alimentación balanceada y correcta en la etapa infantil. En esta etapa, los órganos del cuerpo humano se desarrollan por lo que la ingesta de alimentos debe ser la correcta. Undesequilibrio en esta relación puede ocasionar a futuro la aparición de enfermedades que pueden disminuir la calidad de vida. 


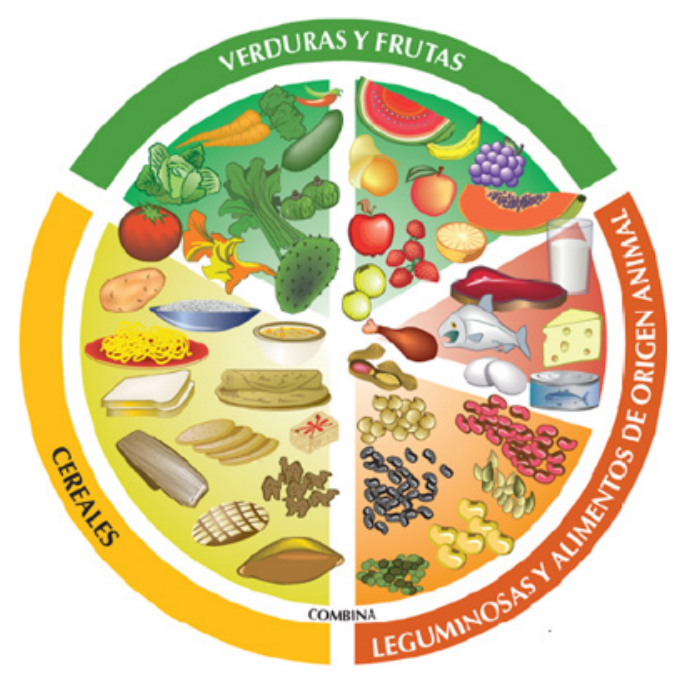

Figura 1. El plato del bien comer donde se muestra los alimentos necesarios para una alimentación correcta

Fuente: (IMSS, 2020)

Es necesario poder encontrar los parámetros que puedan ayudar a obtener el equilibrio entre una buna alimentación-nutrición y los demás aspectos psicosociales que afronta el individuo en su niñez. Esto es porque condicionan el crecimiento y el desarrollo y determinan la óptima realización del potencial genético de cada ser humano(Daza, 1997). La influencia social, genéticas y de ambiente familiar, tienen un impacto relevante sobre el patrón de ingesta, la conducta alimentaria y la obesidad infantil(Jaimovich P., y otros, 2010). En la Tabla 1 se puede visualizar los principales factores de la vulnerabilidad alimentaria nutricional. 
Tabla 1. Principales factores de la vulnerabilidad alimentaria nutricional

\begin{tabular}{|c|c|}
\hline FACTORES & CARACTERÍSTICAS \\
\hline Medioambiental & $\begin{array}{l}\text { Las cifras más altas de desnutrición y mortalidad infantil se observan en } \\
\text { países donde la agricultura a menudo es afectada por desastres naturales. } \\
\text { Los frecuentes embates de huracanes, sequías, terremotos y heladas } \\
\text { generan riesgos "directos", que obstaculizan el acceso a bienes } \\
\text { alimentarios, e "indirectos", debido a los problemas económicos y sociales } \\
\text { derivados de estos eventos. } \\
\text { Por otra parte, el hogar en que habitan niños desnutridos frecuentemente } \\
\text { no dispone de instalaciones adecuadas de agua potable y saneamiento } \\
\text { básico, lo que incrementa el riesgo de contraer enfermedades infecciosas, } \\
\text { principalmente diarreas y parásitos, creándose un círculo vicioso en que el } \\
\text { elemento ambiental es un agente activo en el desarrollo de la desnutrición. }\end{array}$ \\
\hline $\begin{array}{l}\text { Sociales, } \\
\text { culturales y } \\
\text { económicos }\end{array}$ & $\begin{array}{l}\checkmark \text { El bajo nivel de ingresos limita el acceso a los alimentos, en cantidad o } \\
\text { calidad necesarias, o en ambas. } \\
\checkmark \text { La falta de acceso a la tierra afecta a la capacidad de acceso al crédito } \\
\text { y otros recursos, lo que repercute en los ingresos económicos. } \\
\checkmark \text { La sustitución de cultivos tradicionales por cultivos comerciales más } \\
\text { rentables tiende a aumentar la vulnerabilidad nutricional y reducir el } \\
\text { acceso a alimentos en tiempos de caída de precios o crisis económicas. } \\
\checkmark \text { El bajo nivel educativo parental -en especial de la madre- y la falta de } \\
\text { conocimientos sobre salud reproductiva, nutrición y desarrollo infantil } \\
\text { inciden negativamente en la desnutrición de los hijos. En los países } \\
\text { andinos, por ejemplo, la prevalencia de desnutrición global es inferior en } \\
30 \% \text { a } 40 \% \text { entre los niños con madres que cursaron educación primaria, } \\
\text { en comparación con niños de madres que no completaron dicho ciclo. } \\
\checkmark \text { La falta de acceso y la deficiente calidad de los servicios de atención } \\
\text { primaria de salud y de intervenciones específicas en salud y nutrición, } \\
\text { representan otro obstáculo considerable. } \\
\checkmark \text { La condición de pobreza extrema, discriminación y aislamiento } \\
\text { geográfico de los pueblos indígenas son factores relacionados con la } \\
\text { alta prevalencia de desnutrición en dichas poblaciones. En el caso de } \\
\text { los países con una considerable presencia indígena, por ejemplo, la } \\
\text { desnutrición es superior hasta en un } 140 \% \text { entre niños pertenecientes a } \\
\text { hogares indígenas. } \\
\checkmark \text { La pérdida de capital social y la desarticulación de las redes de apoyo } \\
\text { de los más pobres, como consecuencia de procesos migratorios y } \\
\text { conflictos sociales, limitan la capacidad de respuesta colectiva ante } \\
\text { desastres naturales o económicos que dificultan su acceso a los } \\
\text { alimentos. }\end{array}$ \\
\hline Biológicos & $\begin{array}{l}\checkmark \text { Un deficiente estado nutricional materno -como consecuencia de una } \\
\text { mala nutrición previa- aumenta los riesgos de desnutrición intrauterina y } \\
\text { bajo peso al nacer. } \\
\checkmark \text { La ausencia -o insuficiencia- de lactancia materna exclusiva (seis meses) } \\
\text { expone al niño o niña a ingerir alimentos que no satisfacen los } \\
\text { requerimientos nutricionales de esa etapa de desarrollo y sin suficiente } \\
\text { control de higiene. } \\
\checkmark \text { La limitada disponibilidad de alimentos complementarios a la leche } \\
\text { materna -a partir del sexto mes de vida- impide proveer los macro y } \\
\text { micronutrientes necesarios para el desarrollo infantil normal en esta } \\
\text { etapa de máximo crecimiento y desarrollo. }\end{array}$ \\
\hline
\end{tabular}

Fuente: (CEPAL \& UNICEF., 2006) 
"Es en esta etapa cuando se adquieren los hábitos alimentarios que tendrán durante toda su vida; sin embargo, también es una etapa de gran variabilidad debido a la presencia de factores como: el desarrollo económico, avances tecnológicos, la incorporación de la mujer al ámbito laboral, la gran influencia de la publicidad y la televisión, la incorporación más temprana de los niños a la escuela y la mayor posibilidad por parte de los niños de elegir alimentos con elevado aporte calórico y baja calidad nutricional". (Macias M., Gordillo S., \& Camacho R., 2012, pág. 41)

Es decir, se debe buscar la forma de crear en los niños una educación nutricional que les permita tener una salud acorde a su edad y que será reflejo en edades posteriores. Existen tres grupos que influyen directamente en el comportamiento nutricional de los jóvenes, la familia, los medios de comunicación y la escuela. La familia es una fuerte influencia en la dieta de los niños y en sus conductas relacionadas con la alimentación, la publicidad televisiva promueve un consumo alimentario no saludable y la escuela realizaacciones de promoción y prevención a través de contenidos temáticos(Macias M., Gordillo S., \& Camacho R., 2012).

Cualquiera de estas circunstancias altera en el comportamiento del niño arrojando enfermedades como la obesidad o anemia. También una mala alimentación produce impactos en morbimortalidad, educación y productividad, constituyéndoseen uno de los principales mecanismos de transmisión intergeneracionalde la pobreza y la desigualdad(CEPAL \& UNICEF., 2006). Por ejemplo, la anemia incide directamente en el rendimiento escolar y en la calidad de vida, por lo que debe ser atendida con programas que tienen que ver con la orientación para el cambio de dieta, y la fortificación de alimentos(Levy T., 2011).

Para contrarrestar este padecimiento infan- til, es necesario que la familia, como bastión y garante de la salud de los niños, conozca los componentes y grupo de los diferentes alimentos. En la Tabla 2se detalla las fuentes útiles de nutrientes y la Tabla 3 muestra las raciones equivalentes por cada grupo de alimentos para una alimentación correcta.

Aunado a estos cuidados en la alimentación que se debe brindar a la población, y más a la población infantil es necesario que existan políticas de calidad en la producción y transporte de los alimentos, entre otros. Esto con el fin de garantizar la inocuidad que no hagan daño, la salubridad, higiene y el valor intrínseco-características naturales en cuanto a cantidad y calidad de nutrientes de dicho alimento(Hinojosa, Chuquimar, \& Paccha, 2019). 
Tabla 2. Fuentes útiles de nutrientes

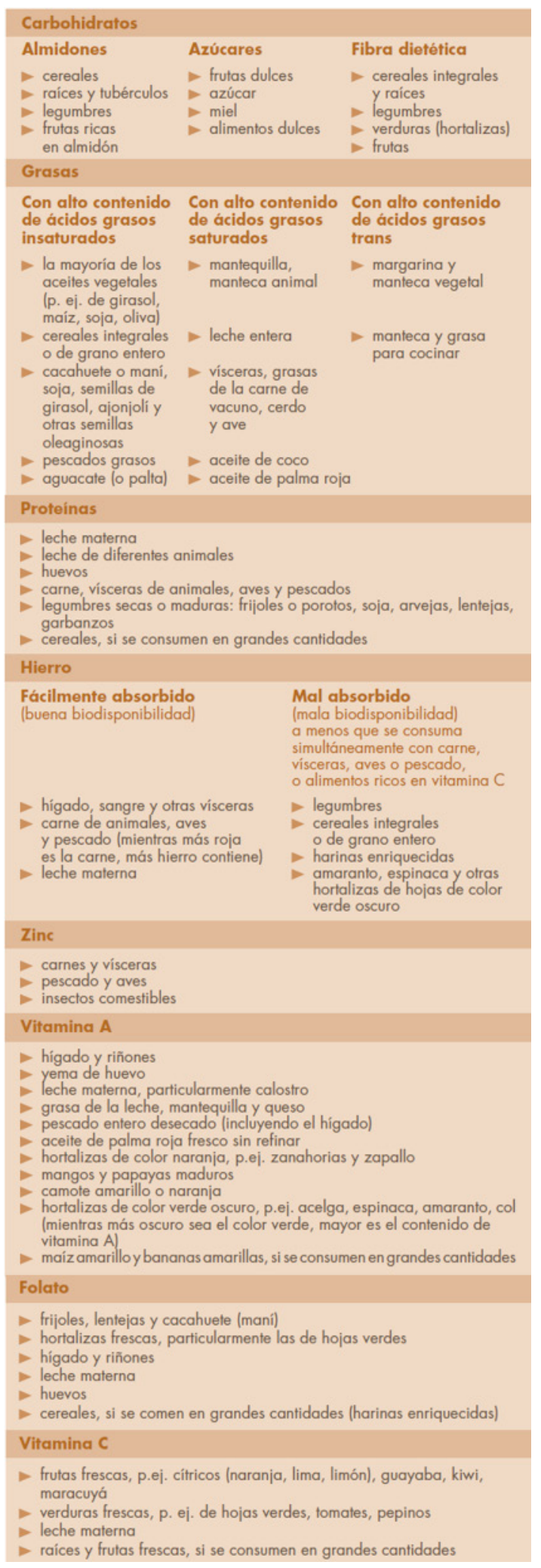

Fuente: (FAO, Nutrientes en los alimentos, 2020) 
Tabla 3. Raciones equivalentes por cada grupo de alimentos para una alimentación correcta

\begin{tabular}{|c|c|c|}
\hline \multicolumn{3}{|c|}{ Grupos de alimentos y ejemplos de equivalencia por ración. } \\
\hline $\begin{array}{l}\text { Grupo de } \\
\text { alimento }\end{array}$ & Ejemplos & $\begin{array}{c}\text { Equivalente a } \\
\text { una ración }\end{array}$ \\
\hline Verduras & $\begin{array}{l}\text { Lechuga, berros o quelites } \\
\text { Espinaca o acelga cruda } \\
\text { Berros, col, flor de calabaza o nopal } \\
\text { Brócoli, calabaza, chayote o zanahoria } \\
\text { Alcachofa, jitomate bola o pimiento } \\
\text { Jugo natural de verdura }\end{array}$ & $\begin{array}{l}3 \text { tazas } \\
2 \text { tazas } \\
1 \text { taza } \\
1 / 2 \text { taza } \\
1 \text { taza } \\
1 / 2 \text { taza }\end{array}$ \\
\hline Frutas & $\begin{array}{l}\text { Frambuesa, melón, papaya, sandía o uva } \\
\text { Ciruela, durazno prisco, guayaba o lima } \\
\text { Durazno amarillo, higo, naranja o tuna } \\
\text { Mandarina reina, mango manila o manzana } \\
\text { Mango petacón, plátano tabasco o pera } \\
\text { Jugo natural de fruta }\end{array}$ & $\begin{array}{l}1 \text { taza } \\
3 \text { piezas } \\
2 \text { piezas } \\
1 \text { pieza } \\
1 / 2 \text { pieza } \\
1 / 2 \text { taza }\end{array}$ \\
\hline Cereales & $\begin{array}{l}\text { Palomitas naturales sin grasa } \\
\text { Arroz cocido o avena cruda } \\
\text { Amaranto tostado } \\
\text { Sopa de pasta, elote o cereal sin azúcar } \\
\text { Pan dulce o pan blanco } \\
\text { Papa o tortilla de harina } \\
\text { Tortillas de maíz o pan de caja } \\
\text { Galletas Marías }\end{array}$ & $\begin{array}{c}21 / 2 \text { tazas } \\
1 / 3 \text { taza } \\
1 / 4 \text { taza } \\
1 / 2 \text { taza } \\
1 / 3 \text { pieza } \\
1 / 2 \text { pieza } \\
1 \text { pieza } \\
5 \text { piezas } \\
\end{array}$ \\
\hline Leguminosas & Frijol, haba, lenteja, alubia o garbanzo & $1 / 2$ taza \\
\hline Leche & $\begin{array}{l}\text { Entera, semidescremada o descremada } \\
\text { Yogurt natural o leche de soya } \\
\text { Yogurt bajo en grasa }\end{array}$ & $\begin{array}{c}1 \text { taza de } 240 \mathrm{ml} \\
1 \text { taza } \\
3 / 4 \text { taza }\end{array}$ \\
\hline $\begin{array}{l}\text { Alimentos de } \\
\text { origen animal }\end{array}$ & $\begin{array}{l}\text { Pescado, pollo, pulpa de res o queso } \\
\text { Clara de huevo } \\
\text { Huevo entero } \\
\text { Jamón de pechuga de pavo }\end{array}$ & $\begin{array}{l}30 \text { gramos } \\
2 \text { piezas } \\
1 \text { pieza } \\
2 \text { rebanadas } \\
\text { delgadas }\end{array}$ \\
\hline Grasas & Aceites en general, mantequilla o crema & $\begin{array}{l}1 \text { cucharadita } \\
\text { cafetera }\end{array}$ \\
\hline Azúcares & $\begin{array}{l}\text { Azúcar, miel, piloncillo, mermelada o } \\
\text { cajeta }\end{array}$ & $\begin{array}{l}1 \text { cucharada } \\
\text { sopera }\end{array}$ \\
\hline
\end{tabular}

Fuente: (IMSS, 2020)

Al no producirse el equilibrio en la alimentación entonces lo que se afronta es un grave problema de desnutrición. La desnutrición infantil es un grave problema. Un niño que sufre desnutrición ve afectada su supervivencia y el buen funcionamiento y desarrollo de su cuerpo y de sus capacidades cognitivas e intelectuales (UNICEF, 2020).

Definitivamente, la falta de nutrientes específicos en el organismo recurre a una falta de desarrollo en los niños que padecen de esta enfermedad. Por ejemplo, el significado importante que tiene la insuficiencia de proteico en esta etapa de desarrollo. Retardo en el crecimiento, el edema, la pigmentación de la piel y la decoloración del pelo, el hígado graso y una elevada letalidad son síntomas de la deficiencia de ingesta de este tipo de alimento lo cual esta determina las características del kwashiorkor(Vega-Franco, 1999).
Por lo tanto, esta investigación tiene como objetivo general analizar la influencia de la desnutrición infantil kwashiorkor. La metodología empleada se baso en investigación de carácter documental y bibliográfica.

\section{Método}

Para el desarrollo metodológico de esta investigación se desarrolló técnicas documentales y bibliográficas a través de textos, documentos y artículos científicos publicados disponibles en la web. Este procedimiento se siguió por medio de los siguientes objetivos específicos como definir la importancia de los alimentos en el desarrollo del cuerpo humano, establecer una diferencia entre nutrición y desnutrición, determinar la influencia delas proteínas en los niños e identificar el kwashiorkor a través de sus causas, síntomas, diagnóstico y tratamiento. 


\section{Resultados}

\section{Desnutrición infantil}

Una de las características más desfavorables para el desarrollo de una nación es su cultura y sus avances para vencer los diferentes problemas socioeconómicos que puedan afectar el libre desenvolvimiento de los ciudadanos. Un reflejo de esta situación es la desnutrición de la población y esta es consecuencia del hambre. Esta empieza a manifestarse cuando el hambre se presenta por periodos prolongados de tiempo, es decir, cuando no hay estabilidad en la disponibilidad, acceso y utilización apropiada de los alimentos(Viera Andrade, 2012).

"Cerca de 200 millones de niños menores de 5 años sufren desnutrición crónica. Un 90\% vive en Asia y África, donde las tasas son muy elevadas: $40 \%$ en Asia y $36 \%$ en África. El $80 \%$ de los niños con desnutrición crónica vive en 24 países. De los 10 países* que más contribuyen a la cifra total, seis están en Asia: Bangladesh, China, Filipinas, India, Indonesia y Pakistán, debido en parte a la elevada población que registran la mayor parte de ellos. Así, por ejemplo, se calcula que 3 de cada 10 niños desnutridos en el mundo en desarrollo viven en India". (UNICEF, 2020, pág. 12)

Ahora, en el continente americano no escapa de esta realidad. La desigualdad social basada en los estratos socioeconómicos, niveles de formación educativa y de desarrollo productivo y tecnológico, aunado a la heterogeneidad de cada región, catalizan este padecimiento en la sociedad. Esto genera problemas en la falta de micronutrientes (hierro, yodo, zinc, vitamina A) y en un exceso creciente de macronutrientes (ricos en grasas saturadas), que se traducen en obesidad y otras patologías(CEPAL \& UNICEF., 2006).

Esto se acelera aún más en la población más vulnerable como lo es la infantil. Es por ello, necesario poder comprender este fenómeno que es una de las principales tragedias a nivel mundial. La desnutrición infantil es el resultado de la ingesta insuficiente de alimentos (en cantidad y calidad), la falta de una atención adecuada y la aparición de enfermedades infecciosas(UNICEF, 2020). En la Figura 2 se puede detallar las causas de la desnutrición infantil.

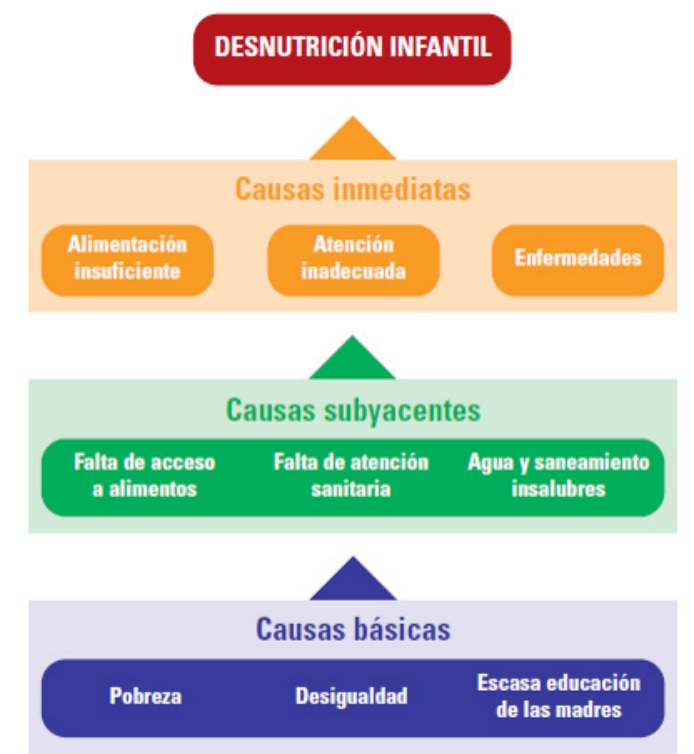

Figura 2. Causas que originan la desnutrición infantil

Fuente: (UNICEF, 2020) 
La desnutrición se manifiesta en el niño de diversas formas:Es más pequeño de lo que le corresponde para su edad, pesa poco para su altura y pesa menos de lo que le corresponde para su edad(UNICEF, 2020). Existen varios tipos de desnutrición infantil, las cuales se detallan en la Tabla 4.

Tabla 4. Tipos de desnutrición infantil

\begin{tabular}{|c|c|}
\hline TIPOS & CARACTERÍSTICAS \\
\hline $\begin{array}{l}\text { Desnutrición } \\
\text { crónica }\end{array}$ & $\begin{array}{l}\checkmark \text { Retraso en el crecimiento. } \\
\checkmark \text { Carencia de los nutrientes necesariosdurante un tiempo prolongado } \\
\checkmark \text { Puede comenzar antes de nacer. }\end{array}$ \\
\hline $\begin{array}{c}\text { Desnutrición } \\
\text { aguda moderada }\end{array}$ & $\begin{array}{l}\text { Un niño con desnutrición aguda moderada pesa menos de lo que le } \\
\text { corresponde con relación a su altura. Se mide también por el perímetro } \\
\text { del brazo, que está por debajo del estándar de referencia. } \\
\checkmark \text { Requiere un tratamiento inmediato para prevenir que empeore. }\end{array}$ \\
\hline $\begin{array}{l}\text { Desnutrición } \\
\text { aguda grave o } \\
\text { severa }\end{array}$ & $\begin{array}{l}\checkmark \text { Es la forma de desnutrición más grave. El niño tiene un peso muy por } \\
\text { debajo del estándar de referencia para su altura. Se mide también por el } \\
\text { perímetro del brazo. Altera todos los procesos vitales del niño y conlleva } \\
\text { un alto riesgo de mortalidad. } \\
\checkmark \text { Requiere atención médica urgente. }\end{array}$ \\
\hline
\end{tabular}

Fuente: (UNICEF, 2020)

En Ecuador se han aplicado una serie de políticas que han permitido la disminución de la desnutrición crónica para niños menores de 5 años, como se observa en la Figura 3, pero no ha sucedido lo mismo en niños menores de 2 años, como se detalla en la Figura 4. Esto significa que tales argumentos políticos no han sido suficientes.Los Programas Sociales de Alimentación y Nutrición del Estado deben redireccionar sus esfuerzos hacia los menores de 5 años con el fin de ejercer un rol de articulación efectiva que permita la utilización de los alimentos según las necesidades nutricionales de cada persona(Viera Andrade, 2012).Estos esfuerzos deben ser canalizados en las zonas rurales de Ecuador debido a que son las más vulnerables para las dos edades estudiadas de los niños, como se visualiza en la Tabla 5.

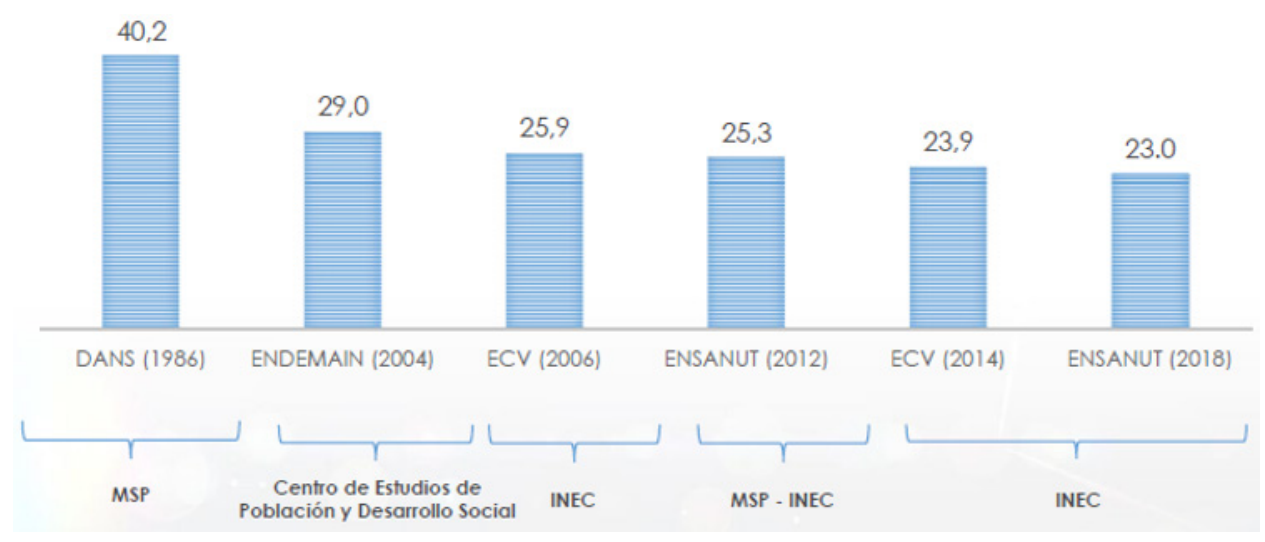

Figura 3. Desnutrición crónica en niños menores de 5 años en el Ecuador.

Fuente: (INEC, Encuesta Nacional de Salud y Nutrición, 2020) 


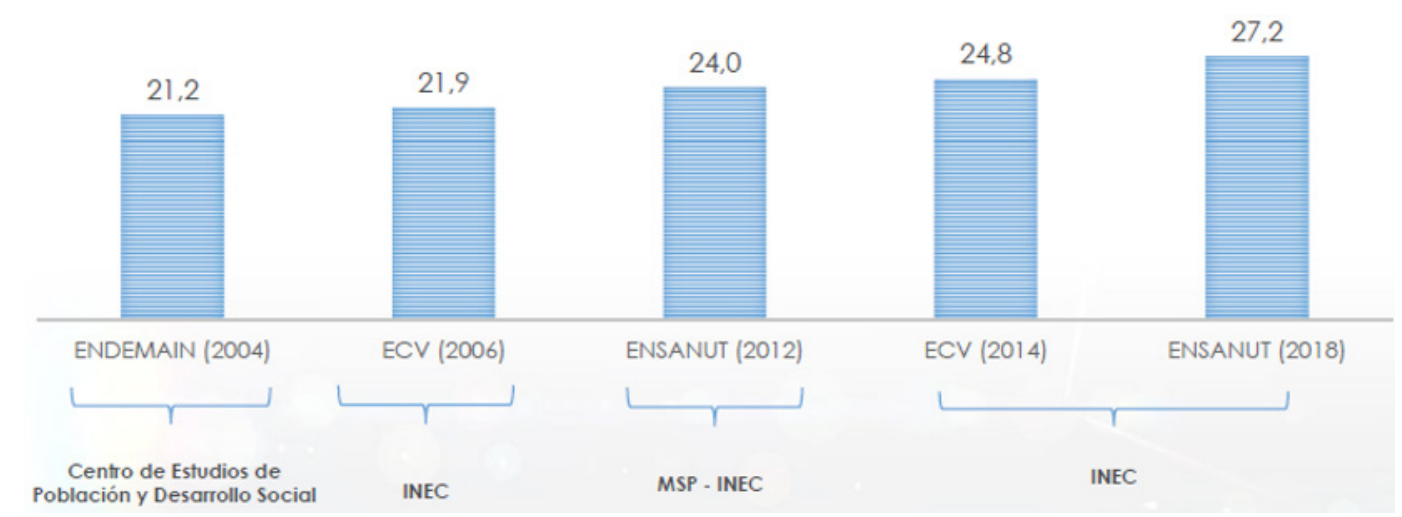

Figura 4. Desnutrición crónica en niños menores de 2 años en el Ecuador

Fuente: (INEC, Encuesta Nacional de Salud y Nutrición, 2020)

Tabla 5. Desnutrición crónica en niños menores de 2 años y 5 años, respectivamente, en las áreas geográficas de Ecuador en los años 2014 y 2018

\begin{tabular}{ccccc}
\hline \multirow{2}{*}{ ÁREA } & \multicolumn{2}{c}{ DESNUTRICIÓN CRÓNICA EN } & \multicolumn{2}{c}{ DESNUTRICIÓN CRÓNICA EN } \\
GEOGRÁFICA & NIÑOS MENORES DE 2 AÑOS & \multicolumn{2}{c}{ NIÑOS MENORES DE 5 AÑOS } \\
\cline { 2 - 5 } & ECV 2014 & ENSANUT 2018 & ECV 2014 & ENSANUT 2018 \\
\hline NACIONAL & 24,8 & 27,2 & 23,9 & 23,0 \\
\hline URBANA & 22,3 & 25,4 & 19,7 & 20,1 \\
\hline RURAL & 29,4 & 30,5 & 31,9 & 28,7 \\
\hline
\end{tabular}

Fuente: (INEC, Encuesta Nacional de Salud y Nutrición, 2018, 2020)

Esta situación de desnutrición crónica se debe a múltiples factores, uno de ellos es la falta de información y educción por parte de la familia y en específico la madre como estandarte y baluarte del hogar. Las mujeresdesnutridas tienen bebés con un peso inferior al adecuado,tal como sucede cada año donde nacen unos 19 millones de niños con bajopeso (menos de 2.500 gramos) en los países en vías de desarrollo(UNICEF, 2020).

Es por ello, que se debe conocer los efectos de la ausencia de las diferentes vitaminas y minerales necesarios para el desarrollo del cuerpo humano. Las consecuencias de la desnutrición crónica pueden ser:

"La desnutrición, al afectar a la capacidad intelectual y cognitiva del niño, disminuye su rendimiento escolar yel aprendizaje de habilidades para la vida. Limita, portanto, la capacidad del niño de convertirse en un adulto que pueda contribuir, a través de su evolución humana y profesional, al progreso de su comunidad y de su país. Cuando la desnutrición se perpetúa de generación en generación, se convierte en un serio obstáculo para el desarrollo y su sostenibilidad". (UNICEF, 2020, pág. 12)

Otro factor es la aparición de anemia para esas edades tempranas.

"La anemia afecta principalmente a los niños menoresde 24 meses y a las mujeres embarazadas, con efectos negativos enel rendimiento escolar y la productividad. La deficiencia de vitaminaA disminuye la capacidad de respuesta a las diferentes infecciones,genera problemas de ceguera y aumenta hasta en un $25 \%$ el riesgode mortalidad materna e infantil. La falta de yodo es la principalcausa de retardo mental y aminora el coeficiente intelectual enaproximadamente 10 puntos".(CEPAL \& UNICEF., 
2006, pág. 8)

Con el finde poder disminuir todos estos efectos y producir verdaderos cambios dentro de la sociedad con la finalidad de evitar, a gran escala, la desnutrición es necesario aplicar ciertas consideraciones a las políticas gubernamentales como se detalla en la Tabla 6.

Tabla 6. Recomendaciones en las políticas para combatir la desnutrición infantil

\begin{tabular}{l}
\hline Promover la lactancia materna (exclusiva hasta los 6 meses de vida), facilitando condiciones \\
laborales apropiadas para la mujer trabajadora con hijos lactantes. \\
\hline Mantener y mejorar los programas de fortificación de alimentos con micronutrientes. \\
\hline Proveer y promover el consumo de suplementos alimentarios para mujeres embarazadas y en \\
período de lactancia, y para niños y niñas lactantes y en edad preescolar. \\
\hline Promover y mejorar las prácticas alimentarias basadas en productos originarios y tradicionales, \\
con alto contenido nutricional, tomando en cuenta la diversidad cultural y étnica. \\
\hline Establecer programas de transferencias monetarias y de alimentos para poblaciones en \\
extrema pobreza. \\
\hline Fortalecer las acciones de prevención, sobre todo por medio de programas de información, \\
educación alimentario-nutricional y comunicación respecto de buenas prácticas de cuidado \\
infantil, higiene, desparasitación, alimentación saludable, manipulación y conservación de \\
alimentos, focalizados en los grupos más vulnerables. \\
\hline Establecer u optimizar los sistemas de protección alimentaria de emergencia ante desastres \\
naturales y conflictos sociales. \\
\hline Mejorar la calidad de la inversión y gestión de los servicios de educación y salud. \\
\hline Facilitar a las familias más vulnerables el acceso a activos productivos relacionados con la \\
tierra, el equipamiento y el financiamiento, junto con programas de mejoramiento de suelos, \\
manejo del agua, almacenamiento y acciones que profundicen la capacidad asociativa y de \\
industrialización de los procesos. \\
\hline Mejorar los procesos productivos de los bienes alimentarios mediante la inversión en nuevas \\
tecnologías, capacitación e higiene. \\
\hline Promover mayores avances en los acuerdos comerciales relacionados con productos \\
alimenticios, especialmente en relación con el efecto de subsidios y otros mecanismos de \\
protección de países desarrollados.
\end{tabular}

Fuente: (INEC, Encuesta Nacional de Salud y Nutrición, 2018, 2020)

\section{Influencia de la proteína en los niños}

El desarrollo de los niños es un progreso constante, la cual requiere de ciertas vitaminas y minerales que permitan poder contrarrestar el gasto energético. Aproximadamente cada año ganan 2 kilos de peso y de 5 a $6 \mathrm{~cm}$ de talla, por lo que la dieta que los pequeños consuman deberá ser adaptada a la actividad que genera la necesidad energética (Realpe Silva, 2014).

Como un papel fundamental es el consumo de energía producto de las actividades diarias es por ello que requieren de ciertos tipos de alimentos que puedan dar equilibrio al organismo. Uno de los papeles funda- mentales es la ingesta de grasa y proteína. Los requerimientos recomendados de energía van de $50 \%$ al $60 \%$, a base de carbohidratos, de $25 \%$ a $35 \%$ a base de grasas y de $10 \%$ a $15 \%$ a base de proteínas(Realpe Silva, 2014).

Una de las características de las proteínas es que tiene como función sustituir ciertos componentes celulares y de tejidos que se descomponen en el cuerpo humano. Las proteínascontienen carbono, hidrogeno, oxígeno, nitrógeno y a menudo azufre, por lo que son el principal componente estructural de las células y los tejidos y constituyen la mayor porción de sustancia de los músculos y órganos (aparte del agua)(FAO, 
Macronutrientes: carbohidratos, grasas y proteínas. Capítulo 9, 2020).El término proteína procede de la palabra griega "protos", que significa 'primera', aludiendo ya por sí misma a su importancia, por lo que ningún organismo podría sobrevivir sin la absorción constante de proteínas(NESTLÉ, 2020).

"Su principal función en el ámbito orgánico es plástica y estructural, no energética. Las proteínas son, sobre todo, esenciales para la creación de los diferentes tejidos y compuestos necesarios para el funcionamiento del organismo, por lo que son esenciales en el crecimiento y el mantenimiento de los tejidos (piel, pelo, uñas, músculo, hueso, etc.) y en la producción de proteínas endógenas (enzimas, hormonas, proteínas transportadoras, inmunoglobulinas, etc.)". (NESVIDA, 2020, pág. 6)

El conocimiento por el efecto de las proteínas sobre el organismo ha venido en crecimiento permitiendo conocer, aún más, la importancia que tiene sobre el organismo, sobre todo el exceso de ingesta de la misma, esto se detalla en la Figura 5.

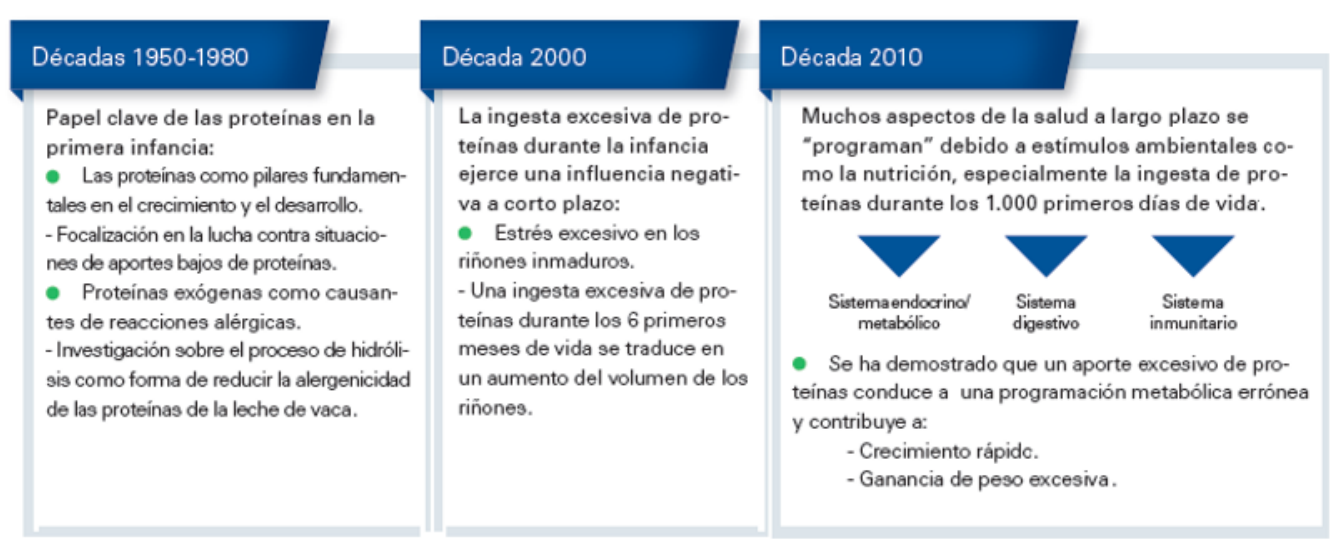

Figura 5. Conocimiento sobre el efecto de las proteínas a largo plazo

Fuente: (NESTLÉ, 2020)

Una de las características fundamentales de las proteínas es que están compuesta por aminoácidos los cuales tienen la capacidad de sintetizar los alimentos que se ingieren. Es decir, la calidad de las proteínas que proporcionan los alimentos depende de los aminoácidos que las componen, así como de su biodisponibilidad(NESVIDA, 2020). Los aminoácidos de cualquier proteína se unen mediante las llamadas uniones peptídicas para formar cadenas, otorgando variedad lo cual permiten múltiples configuraciones y por lo tanto muchas proteínas diferentes (FAO, Macronutrientes: carbohidratos, grasas y proteínas. Capítulo 9, 2020).
Existe diferentes tipos de aminoácidos unos producidos por el cuerpo humano y otros que necesariamente deben ser ingeridos a través de la alimentación. Esto se pueden detallar en la Figura 6. 


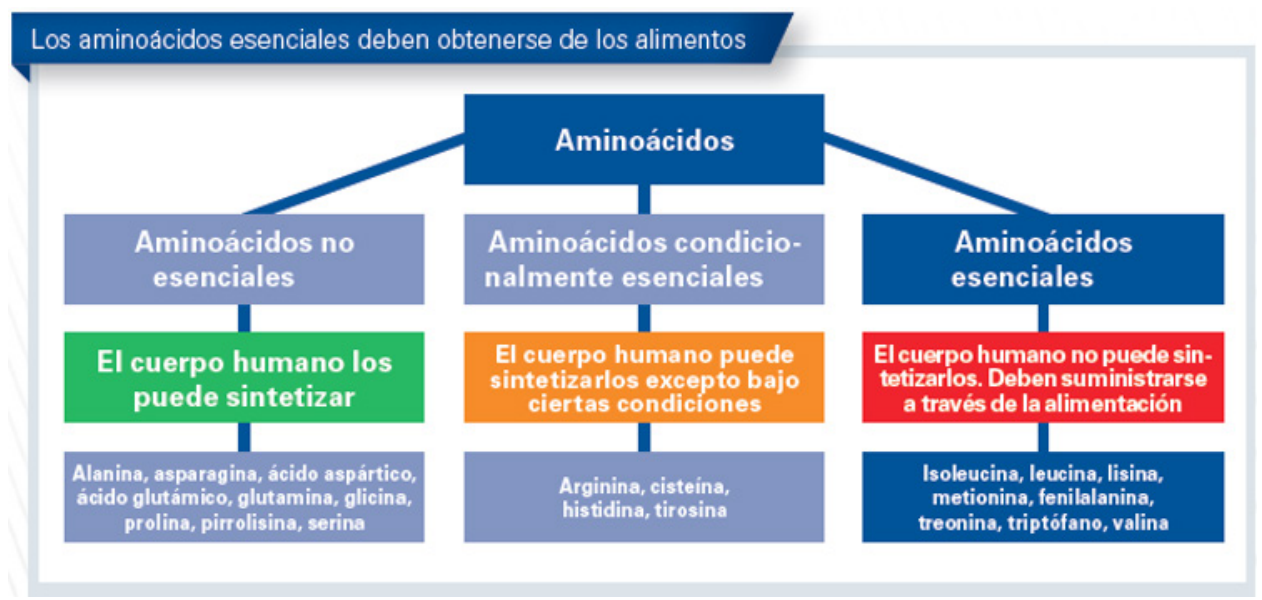

Figura 6. Diferentes tipos de aminoácidos en función de la importancia en el organismo humano

Fuente: (NESTLÉ, 2020)

"Las combinaciones entre los 21 aminoácidos existentes son la base de miles de proteínas diferentes. Ocho de estos aminoácidos son esenciales para la vida, pero no pueden ser producidos por el cuerpo humano y, por ello, se deben absorber a través de la dieta. Estos aminoácidos esenciales son los siguientes: isoleucina, leucina, lisina, metionina, valina, treonina, fenilalanina y triptófano. Para los niños, al menos 12 ami-noácidos son esenciales, ya que su organismo todavía inmaduro no es capaz de producirlos".(NESTLÉ, 2020, pág. 3)

Estas proteínas al entrar en el organismo se cumplen ciertos mecanismos físicos y químicos que permiten obtener los aminoácidos necesarios para el desarrollo del cuerpo humano.La pepsina y la renina del estómago, la tripsina del páncreas y la erepsina de los intestinos, hidrolizan las proteínas en sus componentes, los aminoácidos, los cuales son absorbidos en el intestino delgado, se desplazan al hígado y de allí a todo el cuerpo(FAO, Macronutrientes: carbohidratos, grasas y proteínas. Capítulo 9, 2020).

De todo este proceso, es necesario que exista un equilibrio en el nitrógeno positivo, el cualse ve más afectado en la etapa de crecimiento de los niños, en especial en los primeros 6 meses de vida. Así, los lactantes necesitan proteínas, por kilogramo de peso, superiores a las de los adultos, por lo que la determinación de estas necesidades se basa, lógicamente, en la leche materna(NESVIDA, 2020).

Después de los 6 meses, es necesario una ingesta de proteína a través de una alimentación balanceada. Tanto el desarrollo físico como mental están influenciados en gran parte por la ingesta de proteínas, donde el cuerpo sólo puede almacenar una cantidad limitada y por eso debe recibir un aporte diario de las mismas(NESTLÉ, 2020). Esto se puede observar en la Figura 7, donde se detalla las principales funciones de las proteínas en el cuerpo humano. 


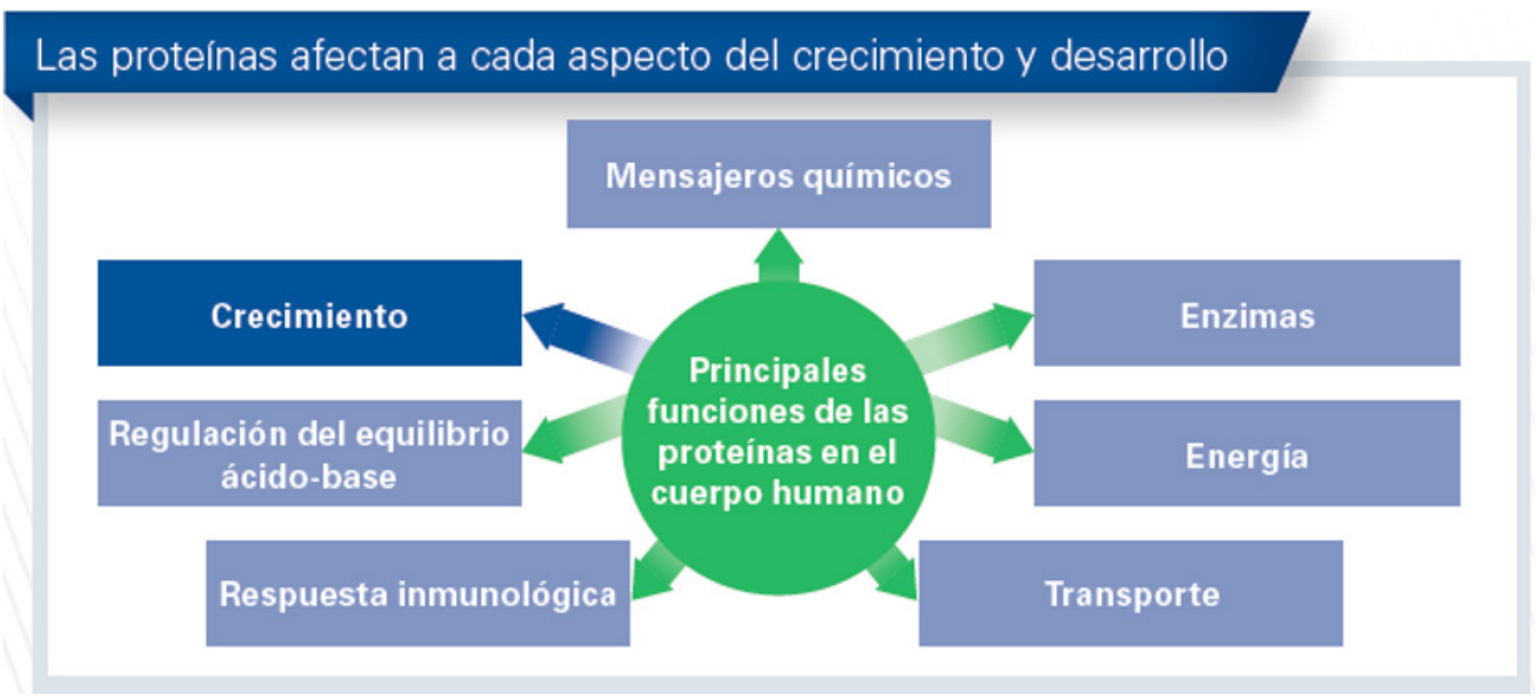

Figura 7. Principales funciones de las proteínas en el cuerpo humano

Fuente: (NESTLÉ, 2020)

\section{Kwashiorkor}

La desnutrición proteico-energética es una falla grave al equilibrio del organismo produciendo alteración en todos los órganos del cuerpo humano. Esto es debido a una ingestión insuficiente, inadecuada absorción, exceso de pérdidas o la conjunción de dos o más de estos factores, por lo que se manifiesta por grados de déficit antropométrico, signos y síntomas clínicos y alteraciones bioquímicas, hematológicas e inmunológicas(Barrionuevo Marín, 2016).

La deficiencia de proteínas en el organismo puede producir desnutrición calórica proteica en el niño en etapa de desarrollo. De esta patología se agrupan los estados de deficiencia que van, desde el niño que es delgado con bajo peso y talla inferior en relación a su edad, hasta las variedades más graves conocidas entre ellas el Kwashiorkor o síndrome pluricarencial grave(Martínez Gavilanes, 2017).

Entonces, es necesario poder comprender el síndrome de kwashiorkor. Se puede definir como la forma grave aguda de la deficiencia energética proteínica(Villazante Apaza \& Torrejón Apaza, 2014).Se caracteriza por la atrofia muscular marcada con la grasa corporal normal o aumentado y la presencia de edema periférico (anasarca) (Barrionuevo Marín, 2016). También, una de las características más notables es la hepatomegalia debido a la infiltración grasa del hígado, lo cual lo puede diferenciar otro tipo de desnutrición Infantil, como el marasmo(FLORES, SEAKINS, \& MONCKEBERG, 1973).

La razón del nombre deriva de la tradición oral ghanesa. Una mujer tuvo dos hijos Kwashie y -Korkor, con intervalo corto entre ambos embarazos, los cuales presentaron hepatomegalia, cabello claro, la piel seca y pies edematizados, por lo que la gente de su localidad se refería a esos síntomas como - Kwashie ke Korkor(Villazante Apaza \& Torrejón Apaza, 2014).

Los primeros estudios se realizaron en África, determinando que muchas de los síntomas presentados en los niños recurrían a una misma patología, kwashiorkor. Los síntomas presentados eran el retardo en el crecimiento, el edema, la pigmentación de la piel y la decoloración del pelo, el hígado graso y una elevada letalidad, por lo que la causa era la deficiencia de proteínas en la dieta(Vega-Franco, 1999).La evolución del conocimiento del kwashiorkor se relacio- 
na al estudio realizado entre 1950 y 1998, como se detalla en la Tabla 7.

Tabla 7. Relación histórica del estudio del Kwashiorkor entre 1950 y 1998

\begin{tabular}{ll}
\hline 1950 & OMS/FAO comisionan a Brock y Autret en Africa. \\
\hline $1950-1960$ & $\begin{array}{l}\text { Intensa actividad en investigación clínica: descripciones clínicas, } \\
\text { anatomopatológicas, fisiopatológicas y respuesta al tratamiento. }\end{array}$ \\
\hline $1960-1970$ & $\begin{array}{l}\text { Se inician lineas de investigación sobre el impacto en el } \\
\text { desarrollo mental y la respuesta inmunológica ante infecciones } \\
\text { intestinales. }\end{array}$ \\
\hline $1970-1980$ & $\begin{array}{l}\text { Hay mayor interés por encontrar indices de valoración } \\
\text { antropométrica más precisos. }\end{array}$ \\
\hline 1987 & $\begin{array}{l}\text { Golden y Ramdath }{ }^{17} \text { proponen que la diferencia entre el } \\
\text { kwashiorkor y el marasmo se puede explicar por el impacto } \\
\text { que ejercen, en la primera de estas formas clinicas, los radicales } \\
\text { libres. }\end{array}$ \\
\hline $1980-1990$ & $\begin{array}{l}\text { La nutrición de la comunidad y la atención primaria cobran } \\
\text { interés. }\end{array}$ \\
\hline
\end{tabular}

Fuente: (Vega-Franco, 1999)

Ahora, el kwashiorkorinteractúa dentro del organismo gracias a 3 mecanismos que interactúan entre sí. a) Disminución de la albúmina sérica (aunque esto también ocurre en el marasmo),b) reducción de la permeabilidad capilar, y c) elevación de las concentraciones de cortisol y de la hormona vasopresina(Villazante Apaza \& Torrejón Apaza, 2014).

"La hormona de crecimiento conduce aminoácidos al tejido muscular magro, lo que impide que haya síntesis de proteínas viscerales y en consecuencia el hígado no sintetiza suficientes lipoproteínas, con lo cual la grasa se queda atrapada en el hígado causando hepatomegalia.

Cuando la carencia de proteínas se prolonga, existe un exceso de ingreso energético a partir de los hidratos de carbono, la respuesta hipo metabólica de adaptación y el inadecuado aumento de cortisol plasmático produce una movilización de proteínas, que disminuyen la albumina plasmática y los aminoácidos, por lo cual puede presentarse una disminución de antioxidantes como el glutatión, selenio y el zinc, así como las vitaminas A, C y E y los ácidos grasos". (Villazante Apaza \& Torrejón Apaza, 2014, pág. 329)

Así mismo, las manifestaciones clínicas se pueden observar en la Tabla 8 las cuales es producto de la evaluación física del paciente. 
Tabla 8. Manifestaciones clínicas del kwashiorkor

\begin{tabular}{|c|c|}
\hline MANIFESTACIÓN & CARACTERÍSTICAS \\
\hline $\begin{array}{l}\text { Crecimiento } \\
\text { insuficiente }\end{array}$ & $\begin{array}{l}\text { Existe una carencia en el crecimiento. Al saber la edad precisa del niño, se } \\
\text { encontrará que es más pequeño de lo normal, excepto en casos de edema } \\
\text { evidente porque este enmascara algunos signos. } \\
\text { Los brazos y piernas del niño son delgados debido a la pérdida de masa } \\
\text { muscular. }\end{array}$ \\
\hline Edema & $\begin{array}{l}\text { Es la acumulación de líquido en los tejidos hace que se edematicen, comenzando } \\
\text { por los miembros inferiores y superiores hacia el centro del cuerpo. }\end{array}$ \\
\hline $\begin{array}{l}\text { Cambios en el } \\
\text { cabello }\end{array}$ & $\begin{array}{l}\text { En el Kwashiorkor, el cabello se vuelve más sedoso, quebradizo, delgado, carece } \\
\text { de brillo, es opaco y sin vida y puede cambiar su color a castaño o castaño rojizo. } \\
\text { Estos últimos tipos de cambios se presentan por la deficiencia del aminoácido } \\
\text { fenilalanina, sustrato principal de la enzima fenilalanina hidroxilasa hepática que } \\
\text { cataliza la reacción de transformación a tirosina que a la vez es sustrato de la } \\
\text { enzima tirosinasa que la transforma en melanina, metabolito deficiente culpable de } \\
\text { los cambios del color del cabello. Algunas veces el pelo se rompe con facilidad } \\
\text { en mechones pequeños. }\end{array}$ \\
\hline Cambios en la piel & $\begin{array}{l}\text { La dermatosis aparece, pero no está presente en todos los casos de Kwashiorkor, } \\
\text { la misma tiende a presentarse primero en las áreas de fricción o de presión, como } \\
\text { las ingles, detrás de las rodillas y en el codo. Aparecen de igual forma parches } \\
\text { pigmentados oscuros, que se pueden descamar con facilidad. }\end{array}$ \\
\hline Hígado & $\begin{array}{l}\text { La hepatomegalia, que es una característica común se produce por el mayor } \\
\text { depósito de triacilgliceroles, con la salida de lipoproteínas, llevando a alteraciones } \\
\text { en la betaoxidación y alteraciones en el metabolismo de drogas }\end{array}$ \\
\hline Cambios mentales & $\begin{array}{l}\text { El niño por lo general es apático con su entorno e irritable cuando se le molesta, } \\
\text { éste suele permanecer en una misma posición y casi siempre está triste, no sonrie } \\
\text { y generalmente no presenta apetito. }\end{array}$ \\
\hline Anemia & $\begin{array}{l}\text { Presentan un grado de anemia debido a la falta de ingesta de las proteínas } \\
\text { necesarias. La anemia se puede complicar por carencia de hierro y enfermedades } \\
\text { concomitantes. } \\
\text { La anemia puede condicionar de igual forma a la presencia de soplos cardiacos. }\end{array}$ \\
\hline Signos bucales & $\begin{array}{l}\text { Presenta queilosis (complicación de la boca y de los labios donde se presenta } \\
\text { una formación de fisuras y escamas provocadas por la deficiencia nutricional) y } \\
\text { atrofia de las papilas en la boca. }\end{array}$ \\
\hline Diarrea & $\begin{array}{l}\text { Son por lo común liquidas y con partículas de alimentos no digeridos con olor } \\
\text { desagradable, en ocasiones son semilíquidas o teñidas con sangre. }\end{array}$ \\
\hline $\begin{array}{l}\text { Sistema } \\
\text { cardiovascular }\end{array}$ & $\begin{array}{l}\text { Existe atrofia del miocardio, en las primeras fases de la enfermedad, pero más } \\
\text { adelante el corazón suele estar aumentado de tamaño, añadiéndose disminución } \\
\text { del débito y volumen de eyección. } \\
\text { Puede presentarse además hipotensión arterial, hipotermia, pulso filiforme, } \\
\text { sonidos cardiacos distantes. }\end{array}$ \\
\hline Sistema renal & Existe atrofia tubular, disminución de la capacidad de concentración urinaria \\
\hline Sistema digestivo & $\begin{array}{l}\text { En las alteraciones gastrointestinales, el estómago presenta atrofia de la mucosa, } \\
\text { por lo que la secreción de ácido clorhídrico disminuye. Existe, dilatación gástrica, } \\
\text { flatulencia, tendencia al vomito, por lo que el niño pierde peso. }\end{array}$ \\
\hline $\begin{array}{l}\text { Sistema nervioso } \\
\text { central }\end{array}$ & $\begin{array}{l}\text { El Kwashiorkor durante los periodos de maduración del cerebro ocasiona; } \\
\text { cambios bioquímicos, modificaciones en la mielinización; una disminución de los } \\
\text { neurotransmisores, del número de células y del ácido desoxirribonucleico } \\
\text { neuronal. } \\
\text { Provocando una disminución del crecimiento, peso del cerebro, así como } \\
\text { alteraciones en la velocidad de la conducción de los estímulos nerviosos. }\end{array}$ \\
\hline
\end{tabular}

Fuente: (Villazante Apaza \& Torrejón Apaza, 2014) 
De aquí, se procede a realizar un diagnóstico a travésde la exploración física y de un interrogatorio al niño y la madre sobre talla, pesos, edad y sexo, aunado al conocimiento sobre la dieta alimenticia del infante con el fin de obtener un diagnostico y así proceder a realizar tratamientos.

"Peso para edad (P/E):Es un indicador de desnutrición global, se utiliza para monitorear el crecimiento, el bajo peso refleja dietas inadecuadas, periodos prolongados de enfermedad entre otras.

Talla para la edad. (T/E):Una talla baja en relación a la edad indica insuficiencia alimentaria crónica que afecta al crecimiento en longitud.

Relación peso talla (P/T):Refleja el estado nutricional actual cuando es bajo indica que la masa muscular y la grasa corporal se encuentran disminuidos, en relación a la talla". (Barrionuevo Marín, 2016, pág. 19)

El tratamiento para el kwashiorkoresta basado en las normativas de la Organización Mundial de la Salud en la lucha contra la desnutrición infantil. Este tratamiento se puede observar a través de la Tabla 9 y se distingue a través de los 10 pasos detallados en la Figura 8. 
Tabla 9. Tratamiento del kwashiorkor, según la OMS

\begin{tabular}{|c|c|}
\hline FASES & CARACTERÍSTICAS \\
\hline Hipoglucemia & $\begin{array}{l}\text { Si el niño está consciente y el resultado del Dextrostix muestra una glucemia }<3 \mathrm{mmol} / \mathrm{l} 0<54 \mathrm{mg} / \mathrm{dl} \text {, } \\
\text { administrar: } \\
\checkmark \quad \text { Un bolo de } 50 \mathrm{ml} \text { de solución de glucosa o sacarosa al } 10 \% \text { (una cucharadita no rasada de azúcar } \\
\text { en 3,5 cucharadas de agua) por vía oral o sonda nasogástrica (NG). } \\
\text { Si el niño está inconsciente, aletargado o tiene convulsiones, administrar: } \\
\checkmark 5 \mathrm{ml} / \mathrm{kg} \text { de glucosa estéril al } 10 \% \text { por vía intravenosa (IV), seguidos de } 50 \mathrm{ml} \text { de glucosa o sacarosa } \\
\text { al 10\% por sonda NG. }\end{array}$ \\
\hline Hipotermia & $\begin{array}{l}\text { Si la temperatura axilar es }<35,0^{\circ} \mathrm{C} \text {, mida la temperatura rectal con un termómetro para bajas } \\
\text { temperaturas. Si la temperatura rectal es }<35,5^{\circ} \mathrm{C} \text { : } \\
\checkmark \quad \text { Empiece a alimentar inmediatamente (o rehidrate si es necesario). } \\
\checkmark \quad \text { Caliente al niño: puede vestirlo completamente (también la cabeza), cubrirlo con una manta caliente } \\
\text { y colocar cerca una lámpara incandescente o un calentador, o colocar al niño directamente sobre el } \\
\text { pecho de la madre (piel contra piel) y cubrirlos a ambos. }\end{array}$ \\
\hline Deshidratación & $\begin{array}{l}\text { Primero, } 5 \mathrm{mg} / \mathrm{kg} \text { de ReSoMal cada } 30 \text { minutos durante } 2 \text { horas, por vía oral o sonda NG. } \\
\checkmark \quad \text { Después, } 5-10 \mathrm{ml} / \mathrm{kg} / \text { hora durante las siguientes } 4 \text { a } 10 \text { horas: la cantidad dependerá de la } \\
\text { apetencia del niño y de las pérdidas en las heces y los vómitos. Si entonces el niño todavía estáa } \\
\text { siendo rehidratado, administre el régimen F-75 en lugar de la solución ReSoMal a las } 4,6,8 \text { y } 10 \\
\text { horas. }\end{array}$ \\
\hline Electrolitos & $\begin{array}{ll}\checkmark & \text { Suplementos de potasio, 3-4 mmol//kg/día. } \\
\checkmark & \text { Suplementos de magnesio, 0,4-0,6 mmol/kg/día. } \\
\checkmark & \text { Para la rehidratación use una solución con bajo contenido de Sodio (por ejemplo, ReSoMal). } \\
\text { Prepare los alimentos sin sal. }\end{array}$ \\
\hline
\end{tabular}

Si el niño no presenta complicaciones aparentes, administrar:

$\checkmark \quad$ El sulfametoxazol trimetoprim suspensión, $5 \mathrm{ml}$ por vía oral dos veces al día durante cinco días si el peso $>4 \mathrm{~kg} ; 0$ o 2,5 $\mathrm{ml}$ dos veces al día durante cinco días si el peso $<4 \mathrm{~kg}$ ( $5 \mathrm{ml}$ es equivalente a 40 mg TMP y 200 mg SMX).

Si hay síntomas que sugieran complicaciones (hipoglucemia, hipotermia, letargo), o para los bebés Antibióticos menores de seis meses de criterios para la atención hospitalaria:

$\checkmark \quad$ La ampicilina (50 mg / kg IM / IV cada seis horas) durante dos días, después amoxicilina (15 mg / kg por vía oral tres veces al día) durante cinco días.

$\checkmark$ Gentamicina $(7,5 \mathrm{mg} / \mathrm{kg}$ IM / IV) una vez al día durante siete días.

Si el niño no mejora dentro de las 48 horas:

$\checkmark \quad$ Añadir cloranfenicol (25 mg / $\mathrm{kg}$ IM / IV cada ocho horas) durante cinco días.

$\checkmark \quad$ Administre: Vitamina A por vía oral el primer día (200 000 UI a niños mayores de 12 meses; 100000 $\mathrm{UI}$ a niños de 6-12 meses, y $50000 \mathrm{UI}$ a niños de 0-5 meses), excepto si tiene constancia de que ya se le haya administrado una dosis el mes anterior.

Micronutrientes $\quad \checkmark$ Durante dos semanas o más, administre todos los días: Suplementos multivitamínicos; $1 \mathrm{mg} / \mathrm{día}$ de ácido fólico (5 mg el primer día); $2 \mathrm{mg} / \mathrm{kg} / \mathrm{día}$ de zinc; 0,3 mg/kg/día de cobre; $3 \mathrm{mg} / \mathrm{kg} / \mathrm{día}$ de hierro, sólo cuando empiece a aumentar de Peso.

Tomar pequeñas pero frecuentes de un alimento de baja osmolaridad y pobre en lactosa

Alimentación por vía oral o NG (no utilizar nunca preparados parenterales)

Alimentación prudente $\quad \checkmark \quad 100 \mathrm{kcal} / \mathrm{kg} / \mathrm{día}$

$\checkmark \quad 1-1,5 \mathrm{~g}$ de proteínas/kg/día

$\checkmark \quad 130 \mathrm{ml} / \mathrm{kg} / \mathrm{d}$ ía de líquido (100 m//kg/día si el niño tiene edema grave).

\begin{tabular}{|c|c|c|}
\hline Crecimiento & $\checkmark$ & $\begin{array}{l}\text { Durante la fase de rehabilitación se necesitan medidas alimentarias enérgicas para conseguir } \\
\text { ingestas muy importantes y un rápido aumento de peso, }>10 \mathrm{~g} / \mathrm{kg} / \text { día. Se inicia con el régimen F-75 } \\
\text { los } 7 \text { primeros días y luego con F-100. } \\
\text { Se pueden administrar papillas o alimentos caseros modificados si tienen concentraciones } \\
\text { comparables de calorías y proteínas }\end{array}$ \\
\hline Apoyo emocional & $\begin{array}{l}\checkmark \\
\checkmark \\
\checkmark \\
\checkmark \\
\checkmark\end{array}$ & $\begin{array}{l}\text { Atención afectuosa. } \\
\text { Un entorno alegre y estimulante. } \\
\text { Ludoterapia estructurada durante 15-30 min/día. } \\
\text { Actividad física tan pronto como lo permita el estado del niño. } \\
\text { Participación de la madre cuando sea posible (por ejemplo, que consuele, alimente, bañe y juegue } \\
\text { con el niño). }\end{array}$ \\
\hline Seguimiento & & $\begin{array}{l}\text { iar a los padres o cuidadores: a alimentar frecuentemente al niño con comidas ricas en calorías y } \\
\text { ntes, a realizar una ludoterapia estructurada. }\end{array}$ \\
\hline
\end{tabular}

Fuente: (Barrionuevo Marín, 2016) 


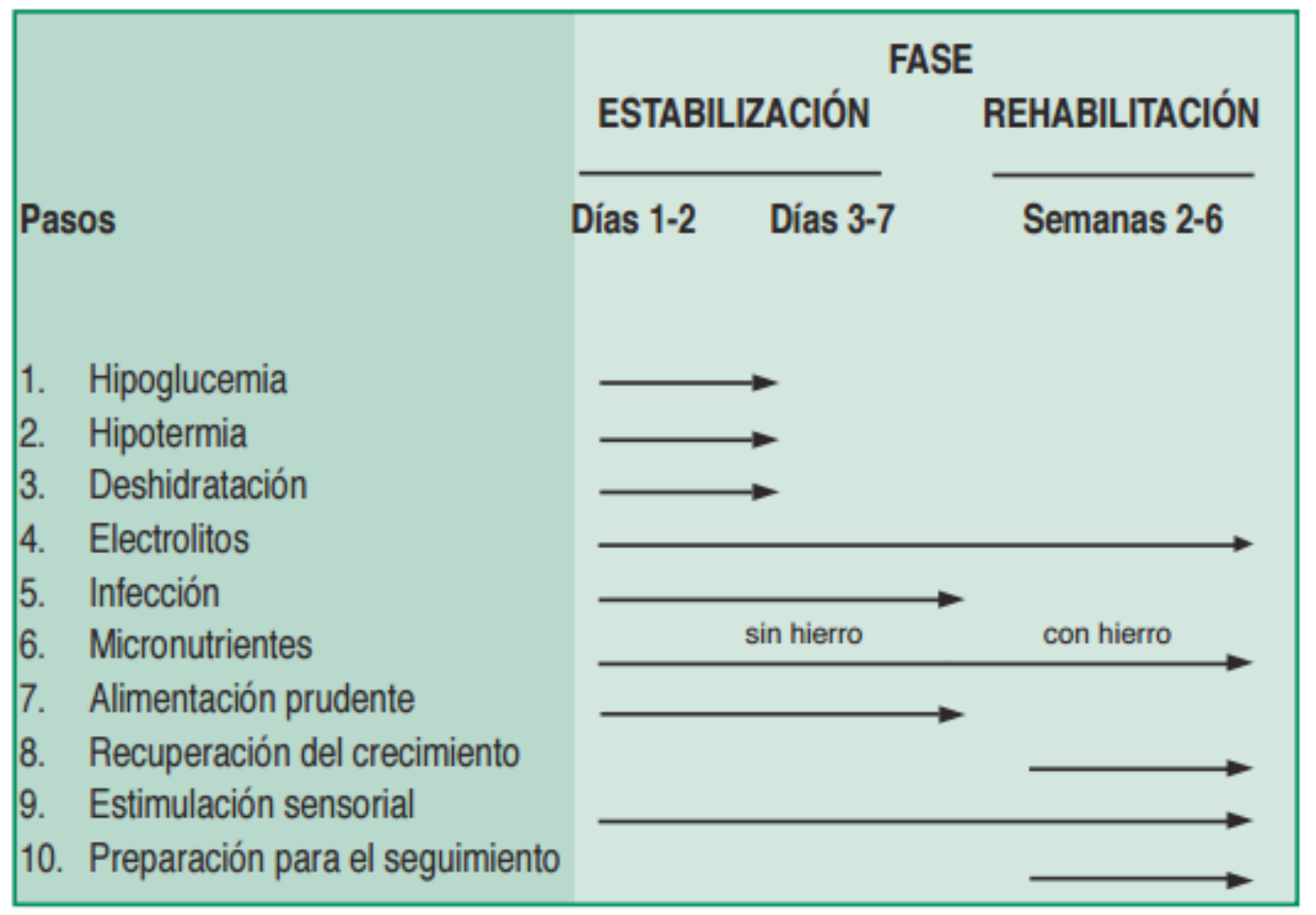

Figura 8. Protocolo de tratamiento según la OMS

Fuente: (Barrionuevo Marín, 2016)

Así mismo, con la voluntad de los familiares y el círculo cercano al niño también debe existir voluntad en las políticas de los entes gubernamentales con el fin de evitar que este tipo de enfermedad siga en aumento en nuestro continente. Hasta ahora ninguna enfermedad endémica se ha erradicado sólo con conocimientos científicos y menos todavía si no se modifica positivamente la calidad de vida de los segmentos de población más desprotegida(Vega-Franco, 1999).

\section{Discusión y conclusiones}

La alimentación es uno de los factores más importantes en el desarrollo del individuo. Debe ser balanceada y correcta en la distribución delos nutrientes necesarios para el completo funcionamiento del organismo. El aparato digestivo procesa los alimentos, donde el hígado y la vesícula juega un papel importante. Esta última segrega la bilis para que puedan obtenerse las vitaminas y minerales vitales para el equilibrio del cuer- po humano. cuando hay desequilibrio en este balance entonces empieza a padecer diversas patologías.

La causa de múltiples patologías es la desnutrición. Esta es producida por la perdida de cantidad total o parcial de los alimentos necesarios en el organismo. Esta enfermedad es más severa dentro del desarrollo de lo individuos, es decir en la etapa de la niñez, debido a la necesidad frecuente de los nutrientes necesarios para el desarrollo psicomotor e intelectual de la persona. Uno de los factores más perjudiciales es la deficiencia en el consumo de proteína. Esta otorga la energía necesaria para el normal desenvolvimiento del niño.

La falta de proteína, y en este caso los aminoácidos, producen una variedad de síntomas como falta de talla o peso, cambios en el cabello y piel, anemia, diarrea, cambios psicológicos y alteración de los aparatos cardiovasculares, digestivos y del sistema nervioso. Existen 21 aminoácidos que pro-

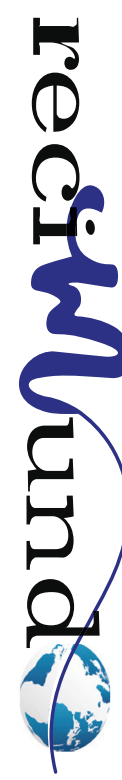


ducen las proteínas del cuerpo humano ero de esos 8 son esenciales y deben ser ingeridos porque el metabolismo no los puede generar. Es aquí donde los proteicos juegan el papel importante.

Por ejemplo, en Ecuador ha disminuido la desnutrición infantil en los niños menores de 5 años, pero no así en los niños menores de 2 años. Esto quiere decir que los diagnósticos realizados a los niños de 1000 días de nacido han permitido el cambio en la perspectiva familiar y social de la población. Por supuesto han existido políticas gubernamentales en pro de ayudar a las familias mas desfavorecidas y con ello a disminuir este flagelo mas no es suficiente, se requiere de un cambio de mentalidad y hasta de paradigmas sociales, sobre todo en las zonas rurales ecuatorianas.

De esta circunstancia recae la problemática sobre la desnutrición proteica infantil, denomina kwashiorkor. Existen múltiples causas, desde las condiciones socioculturales, económicas y de formación educativa que no ha permitido erradicar este problema. La falta de proteínas en esta etapa tan importante puede producir una falta de desarrollo cognitivo y físico a lo largo del tiempo. El diagnóstico es una exploración físicaal niño, midiendo talla y peso para relacionarlo con la edad y el sexo, aunado a un interrogatorio a la madre sobre la dieta alimentaria. El tratamiento es basado en un protocolo otorgado por la OMS, basado en la severidad del diagnóstico y trata principalmente en la atención de la hipoglucemia, deshidratación, electrolitos, alimentación prudente, crecimiento y apoyo emocional.

\section{Bibliografía}

Alvídrez-Morales, A., González-Martínez, B. E., \& J.S. Z. (2002). TENDENCIAS EN LA PRODUCCIÓN DE ALIMENTOS: ALIMENTOS FUNCIONALES. RESPYN. Revista de Salud Pública y Nutrición. Vol 3 No.3, 1-6.

Barrionuevo Marín, M. E. (2016). Desnutrición Infantil Marasmo y Kwashiorkor. Ambato, Ecuador: Trabajo de Grado - Universidad Técnica de Ambato-Fa- cultad de Ciencias de la Salud-Carrera Medicina.

CEPAL, \& UNICEF. (2006). Desnutrición infantil en América Latina y el Caribe. Desafíos, Número 2., $1-12$.

Cide@d. (22 de Febrero de 2020). Los alimentos. Obtenido de http://recursostic.educacion.es/secundaria/edad/3esobiologia/3quincena7/pdf/pdf_ q7.pdf

Daza, C. H. (1997). Nutrición infantil y rendimiento escolar. Colombia Médica Vol. 28 № 2, 92-98.

FAO. (23 de Febrero de 2020). Macronutrientes: carbohidratos, grasas y proteínas. Capítulo 9. Obtenido de Nutrición humana en el mundo en desarrollo: http://www.fao.org/tempref/docrep/fao/005/ w0073s/W0073S01.pdf

FAO. (22 de Febrero de 2020). Nutrientes en los alimentos. Obtenido de http://www.fao.org/3/y5740s/ y5740s16.pdf

FLORES, H., SEAKINS, A., \& MONCKEBERG, F. (1973). El hígado graso en el Kwashiorkor. Revista chilena de pediatría, 44(5), 463-469.

Hernandes, J. C., \& Armaiz, M. G. (2007). Alimentación y cultura. Perspectivas antropológicas. Investigaciones Sociales, 11(19), 387-392.

Hinojosa, L. A., Chuquimar, R. D., \& Paccha, K. G. (2019). Administración de servicios de alimentos: Nutrición, Calidad y Producción. RECIMUNDO, 3(3 ESP), 52-76.

IMSS. (22 de Febrero de 2020). Nutrición. Obtenido de Instituto Mexicano de los Seguros Sociales: http://www.imss.gob.mx/sites/all/statics/salud/ guias_salud/adolescentes/guiaadolesc_nutricion. pdf

INEC. (22 de Febrero de 2020). Encuesta Nacional de Salud y Nutrición. Obtenido de ENSANUT, 2019: https://www.ecuadorencifras.gob.ec/documentos/ webinec/Estadisticas_Sociales/ENSANUT/ENSANUT_2018/Principales\%20resultados\%20ENSANUT_2018.pdf

INEC. (22 de Febrero de 2020). Encuesta Nacional de Salud y Nutrición, 2018. Obtenido de Boletin Técnico de los Indicadores de Salud y Nutrición de la Población Ecuatoriana: https://www.ecuadorencifras.gob.ec/documentos/webinec/Estadisticas Sociales/ENSANUT/ENSANUT_2018/Boletin\%20 ENSANUT\%2028_12.pdf

Jaimovich P., S., Campos S., C., Campos S., M. S., Moore B., J., Pawloski R, L., \& Gaffney F., K. (2010). Estado nutricional y conductas asociadas a la nutrición en escolares. Rev. Chil. Pediatr, 81(6), 515- 
522.

Levy T., S. (2011). PÁGINAS DE SALUD PÚBLICA. salud pública de méxico / vol. 53, no. 1, 98-99.

Macias M., A. I., Gordillo S., L. G., \& Camacho R., E. J. (2012). Hábitos alimentarios de niños en edad escolar y el papel de la educación para la salud. Rev Chil Nutr Vol. 39, №3, 40-43.

Martínez Gavilanes, T. M. (2017). Análisis de "desnutrición crónica tipo kwashiorkor enfocado en los cuidados de enfermería. Ambato, Ecuador: Trabajo de Grado - Universidad Técnica de Ambato-Facultad de Ciencias de la Salud-Carrera de Enfermería.

NESTLÉ. (22 de Febrero de 2020). Las proteínas: un nutriente esencial. Obtenido de Noticias científicas. : https://www.nestlenutrition-institute.org/docs/default-source/spain-documentlibrary/publications/ secured/718329956b00edb151d715061bcfbf09. pdf?sfvrsn=0

NESVIDA. (23 de Febrero de 2020). El papel de la proteínas en la infancia. Obtenido de NESTLÉ NUTRITION INSTITUTION: https://www.agustoconlavida.es/media/nutricion/revista-nesvida/Nesvida_15.pdf

Realpe Silva, F. G. (2014). Influencia de conocimien- tos, actitudes y prácticas alimentarias de los cuidadores en el hogar, en el estado nutricional de los niños y niñas en edad preescolar que asisten al centro de desarrollo infantil Arquita de Noé en el periodo julio-noviembre 2013. Quito, Ecuador: Trabajo de Grado - Pontificia Universidad Católica del Ecuador, FACULTAD DE ENFERMERÍA.

UNICEF. (22 de Febrero de 2020). LA DESNUTRICIÓN INFANTIL. Causas, consecuencias y estrategias para su prevención y tratamiento, 2011. Obtenido de ttps://www.unicef.es/sites/unicef.es/ files/Dossierdesnutricion.pdf

Vega-Franco, L. (1999). Hitos conceptuales en la historia de la desnutrición proteico-energética. Salud Pública de México / vol.41, no.4, 328-333.

Viera Andrade, R. C. (2012). La alimentación saludable como pilar fundamental del desarrollo y el bienestar: análisis de los programas sociales de alimentación y nutrición del estado ecuatoriano y la forma en que abordan el problema de la desnutrición en el Ecuador. Quito, Ecuador: Trabajo de Grado - FLACSO Sede Ecuador.

Villazante Apaza, E., \& Torrejón Apaza, R. (2014). Kwashiorkor. Revista de Actualización Clínica Investiga, 328., 328-334.

\section{CITAR ESTE ARTICULO:}

Andrea Enriqueta, N., Alcivar Cruz, V., Rodriguez Villamar, T., \& Betancourt Bohórquez, F. (2020). Desnutrición infantil kwashiorkor. RECIMUMDO, 4(1(Esp)), 24-45. doi:10.26820/recimundo/4.(1).esp.marzo.2020 